\title{
Aprofundamento de uma estratégia de classificação para podcasts na educação
}

\section{Resumo}

As estratégias de classificações referentes ao podcast, tecnologia de oralidade distribuída sob demanda, encontram-se ainda em estágio inicial de desenvolvimento no âmbito da educação, o que ocasiona uma significativa limitação ao desenvolvimento do pensamento educativo acerca da tecnologia supracitada. Por essa razão, o presente estudo visa aprofundar um sistema classificativo previamente elaborado (FREIRE, 2014). Para tanto, serão analisadas as implicações que a constituição produtiva dos podcasts possui nas aplicações educacionais destes, de modo a classificar as especificidades dos usos educativos daquela tecnologia. Para o alcance desse intento, será feito uso de um aparato metodológico composto por uma pesquisa bibliográfica, abordando estudos sobre o uso educativo da tecnologia aqui tratada, bem como por uma observação participante, direcionada ao cenário nacional de podcasts e dedicada a levantar as possibilidades de uso de tal tecnologia. Como resultado, chegou-se a um sistema de classificações focado nas implicações educacionais práticas advindas da diversidade dos modos de utilização do podcast.

Palavras-chave: Podcast; Tecnologia Educacional; Ensino auxiliado por computador; Oralidade Digital.
Eugênio Paccelli Aguiar Freire Doutor em Educação pela Universidade Federal do Rio Grande do Norte - UFRN - Brasil paccellifreire@gmail.com

\section{Para citar este artigo:}

FREIRE, Eugênio Paccelli Aguiar. Aprofundamento de uma estratégia de classificação para podcasts na educação. Revista Linhas. Florianópolis, v. 16, n. 32, p. 391 - 411, set./dez. 2015. 


\title{
Deepening a podcast's classification strategy in education
}

\begin{abstract}
Strategies related to classify podcast, orality technology distributed on demand, are still in early stages of development in education, which causes a significant limitation to the development of educational thinking about that technology. Therefore, this study aims to deepen a previously developed classification system (FREIRE, 2014). For this, we analyzed the implications of the productive formation of podcasts in educational applications of these productions in order to classify the characteristics of the educational uses of that technology. To achieve the above purpose, use will be made of a methodological apparatus consists of a literature survey, addressing studies about the educational use of technology discussed here, as well as participant observation, looking to the national scenario and podcasts dedicated to raising the possibilities of use of podcast. As a result, we reached a classification system focused on practical educational implications arising from the diversity of modes of podcast's uses.
\end{abstract}

Keywords: Podcast ; Educational Technology ; Assisted by computer education; Orality Digital . 
É sensato afirmar que as literaturas brasileiras e portuguesas, que examinam educativamente o podcast, encontram-se em um estágio inicial de desenvolvimento. Frente à análise de outras tecnologias aplicadas na educação, das mais antigas - como rádio e TV - até as mais recentes - como o blog -, o campo que discute o podcast ainda apresenta uma "escassez de estudos e investigações realizados em Portugal [...] e [...] escassez relativa dos estudos conduzidos no Brasil sobre esta temática" (BOTTENTUIT JUNIOR; LISBÔA; COUTINHO, 2009, p. 297). Nessa área incipiente, os estudos que tratam da classificação de podcasts educacionais não constituem exceção, sendo ainda relativamente poucos.

Dos trabalhos classificativos aludidos, dois foram investigados pelo artigo que precede o presente estudo. Naquela investigação (FREIRE, 2013C), as estratégias classificativas de Medeiros (2005) e Carvalho; Aguiar; Maciel (2009) foram objetos de uma análise que concluiu haver nesses estudos a falta de um critério uniforme, comprometendo, assim, a coerência das classificações elaboradas (FREIRE, 2013C, p. 717718). Por essa razão, o trabalho que analisou as taxionomias dos estudiosos citados prestou-se ao desenvolvimento uma estratégia que considerou os aspectos produtivos dos programas educacionais como critério balizador das classificações propostas. Este direcionamento foi tomado em vista da percepção da forte influência que os aspectos produtivos demonstraram possuir na determinação das características educativas de podcasts (FREIRE, 2013c, p. 725). Foi desenvolvido, por essa razão, um sistema de classificações organizado em torno dos aspectos aludidos, designando os podcasts como Ampliação Tecnológica (voltado a transpor conteúdos de outras tecnologias para podcast), Registro (constituído pela captura de falas realizadas em contexto escolar) e Produção Original (realização desenvolvida originalmente para podcast).

As limitações advindas da delimitação teórica do estudo que elaborou a referida classificação, todavia, ocasionaram nesta a falta de um aprofundamento relacionado às utilizações educacionais específicas que cada tipo de podcast pode propiciar. Afinal, dentro de um podcast Produção Original, por exemplo, é possível realizar programas voltados para a veiculação de informes da escola, para disseminar a opinião de alunos em 
debate sobre um tema determinado, ou, ainda, pode servir para a veiculação de uma exposição docente, dentre diversas outras utilizações pedagógicas notadamente distintas entre si.

Por essa razão, o presente estudo visa desenvolver o aprofundamento da estratégia classificativa apresentada, elaborando, para isso, classificações relacionadas a usos educacionais específicos que se inserem nos tipos de podcasts previamente definidos. Dessa forma, poderá ser disposta uma consonância entre a taxonomia elaborada anteriormente e a que será desenvolvida a seguir, colaborando, assim, para a maturação de uma estratégia classificativa coesa e educativamente relevante.

\section{1 - Aspectos metodológicos}

Será esclarecido neste momento o aparato metodológico que guiará a presente pesquisa. Para tanto, inicialmente será apresentado o podcast, de modo a definir a ótica educativa pela qual este estudo considera a tecnologia em questão. Em seguida, serão descritos o marco teórico que oferecerá alicerce a este estudo, bem como o caminho metodológico que guiará o desenvolvimento da taxonomia proposta. Por fim, será aclarada a estrutura do sistema classificatório a ser elaborado.

\section{1 - A tecnologia podcast}

Não seria inadequado afirmar que de um ponto de vista técnico, o podcast consiste em "um processo mediático que emerge a partir da publicação de arquivos de áudio na internet" (PRIMO, 2005, p. 17). Embora existam podcasts destinados apenas à veiculação de músicas, a maioria dessas produções realiza-se por meio de falas dos participantes, promovendo exposições de conteúdos, relatos de acontecimentos, batepapos ou debates informativos sobre os temas mais diversos.

É apresentada aqui uma tecnologia recente, cuja origem remonta ao ano de 2004. Em relação aos seus aspectos técnicos e a origem de sua palavra peculiar, Ketterl; Mertens; Morisse (2006, p. 2,) explicam que "o termo podcast descreve a produção, 
distribuição e download automático de arquivos de áudio de quem publica até o assinante, pela internet ( tradução nossa)"1'. Desta feita, enquanto na rádio os programas são transmitidos em um determinado horário, obrigando o ouvinte a estar disponível naquela hora ou, de outra forma, não irá poder ter acesso ao conteúdo, no podcast, o programa, também chamado episódio, é distribuído de modo a ser baixado exatamente como um arquivo de música. Este, dentre outros fatores que não poderão ser analisados neste estudo em vista de suas delimitações, constituem o podcast como uma tecnologia que, embora detenha semelhanças ao rádio, destaca-se como uma esfera produtiva notadamente distinta da radiofônica, marcando ambas como tecnologias educacionais particulares (FREIRE, 2012, p. 19).

Além de poder ser descarregado como qualquer outro arquivo, clicando-se em um link postado em site ou blog, o podcast também propicia uma recepção periódica de modo automatizado através de um sistema de RSS ${ }^{2}$. Na verdade, essa função, que habilita a possibilidade de assinatura de um podcast e, igualmente, colabora ao estabelecimento de uma periodicidade em sua publicação, foi o critério original a diferenciar qualquer postagem de áudio em um blog - conhecidas como audioblogs - de um podcast.

A miniaturização dos dispositivos de áudio, bem como a incorporação de funções de tocador de MP3 em telefones celulares, aparelhos de $\mathrm{MP}^{3}$ e até mesmo em algumas câmeras fotográficas digitais, associa a execução e gravação do podcast a diversos aparelhos, além de possibilitar sua escuta em inúmeras situações e momentos do dia a dia.

Os softwares necessários para a realização dos programas também são simples e, alguns deles, gratuitos (CRUZ, 2009, p. 76). A viabilidade financeira da produção em podcast ressalta-se também pela possibilidade de sua disponibilização on-line sem custos. Isso ocorre em função da presença de diversos serviços de armazenamento automatizado gratuitos de podcasts, como os americanos PodOmatic ${ }^{4}$ e PodBean 5 , o

\footnotetext{
1 The term podcasting describes the production, distribution and the automatic download of audio data from a publisher to a subscriber over the internet.

2 Abreviação de "really simple syndication", que significa "distribuição realmente simples". Trata-se de uma ferramenta que permite a assinatura de conteúdos digitais periódicos, os quais são recebidos quando de sua atualização. A funcionalidade é utilizada costumeiramente para a assinatura de blogs e podcasts.

3 Formato digital que comporta, além de áudio, vídeo.

4 Disponível em: $\langle w w w$.podomatic.com $>$.

5 Disponível em: <www.podbeam.com>.
} 
mexicano Poderato ${ }^{6}$ e o brasileiro PodcastOne ${ }^{7}$, que dispõem de sistemas intuitivos para postagem de podcasts.

Em vista do exposto, o podcast desvela facilidades de produção e acesso justificantes de sua larga disseminação e oferecimento de novas possibilidades educacionais práticas. Nesse contexto, apesar dos aspectos técnicos de vinculação a arquivos digitais de áudio, a tecnologia aqui tratada dispõe de uma modalidade voltada para deficientes auditivos, o “podcast para surdos”. Essa realização consiste na transcrição das falas dos programas para texto, realizada a partir do cuidado em preservar a oralidade das expressões transcritas por meio da manutenção do modo expressivo próprio dos podcasters (FREIRE, 2011, p. 201) - termo que define aqueles que produzem podcasts.

Assim, a consideração de um entendimento educacional unificador das esferas sonoras e escritas do podcast possibilita que essa tecnologia seja entendida além de seu foco técnico. Por essa ótica, o podcast é caracterizado não como uma tecnologia de áudio, mas de oralidade (FREIRE, 2013b, p. 42). Além disso, suas características apresentadas repercutem no Brasil em um exercício tecnológico "permeado pela pluralidade, pelas possibilidades de expressão livre, pela ausência da hierarquia típica da separação entre falantes - produtores - e ouvintes - audiência -, expediente regular das mídias comerciais" (FREIRE, 2013e, p. 104). Em vista disso, o podcast é constituído como uma tecnologia essencialmente livre, razão pela qual se torna sensato defini-lo como um “modo de produção/disseminação livre de programas distribuídos sob demanda e focados na reprodução de oralidade, também podendo veicular músicas/sons" (FREIRE, 2013b, p. 47).

A partir das perspectivas expostas, o podcast ganha importância como recurso educacional em vista das características descritas tornarem aquela tecnologia apta a propiciar novos modos de realização de atividades educacionais. No âmbito escolar, como já observado anteriormente, o uso do podcast pode contemplar ações de ampliação temporal, associando à audição de falas expositivas a diversos tempos e espaços pelo uso de arquivos digitais de áudio, além de prover o reaproveitamento de 
materiais de outras tecnologias, como o rádio, entre outros usos afins (FREIRE, 2013a, p. 6-8).

Fora de contextos formais, o podcast corriqueiramente constitui-se em mote para reunião de Sujeitos que, compartilhando um gosto em comum por um tema abordado em um podcast, acabam exercitando um diálogo educacional nas seções de comentários dos blogs das produções, por fóruns de redes sociais aglutinadores dos ouvintes de um programa, bem como por meio do contato direto com os produtores (FREIRE, 2013e, p. 122). Por tais quesitos, constata-se que o podcast potencializa ações educacionais interessantes, diversificadas e ricas.

\section{2 - Marco teórico: perspectiva educacional}

O presente estudo parte de uma concepção educacional pautada por uma perspectiva progressista. Esta, amparada nas concepções de Paulo Freire (2003), concebe a educação como processo de maturação da leitura de mundo dos Sujeitos, dado em uma perspectiva dialógica a partir do pensamento conjunto e igualitário entre os envolvidos, construtores do conhecimento pela convivência no mundo a ser lido e (re)construído concomitantemente.

Portanto, a educação caracteriza-se nesta ótica como um exercício não exclusivo dos contextos formais, embora tenha na escola âmbito privilegiado de desenvolvimento. Tal noção sustenta a relevância de que os fenômenos educacionais que ocorrem em contextos não formais sejam apropriados pela escola.

\section{3 - Caminho metodológico}

A partir do marco teórico definido, a elaboração das classificações aqui designadas buscará subsídios no exercício educacional do podcast ocorrido tanto em contextos escolares quanto não escolares. Em razão disso, torna-se necessário apresentar as estratégias que guiam o olhar lançado às práticas educacionais com o podcast nos dois contextos citados. 
No campo escolar, partiu-se da consideração de experiências analisadas em pesquisas brasileiras e portuguesas, com ênfase nestas últimas. Tal posicionamento deveu-se ao maior desenvolvimento português da utilização pedagógica do podcast, a qual, embora se apresente em um estágio inicial em ambos os países, carece especialmente no Brasil de um maior número de iniciativas escolares.

Foi por tal razão que, no âmbito nacional, o presente estudo focou-se no exercício dado fora dos contextos escolares, realizado na podosfera, termo que designa o cenário brasileiro de podcasts. O olhar aludido foi posto em curso na tese que origina tanto a estratégia classificativa da qual parte a aqui desenvolvida, quando esta própria. 0 trabalho de doutoramento referido é o estudo Podcast na educação brasileira: natureza, potencialidades e implicações de uma tecnologia da comunicação (FREIRE, 2013d).

O olhar em questão ocorreu por meio de uma observação participante, segundo os parâmetros definidos por Peruzzo (2006, p. 125). O procedimento foi viabilizado pela audição por parte do pesquisador de cerca de cinco centenas de programas em podcast. A partir disso, ocorreu a participação daquele estudioso nos grupos de audiência dos programas. Vale salientar que o foco do olhar descrito direcionou-se aos podcasts "não comerciais", referidos neste texto apenas pelo termo podcasts. Essa decisão foi tomada em razão de tais produções constituírem a principal modalidade de uso de tal tecnologia no país (FREIRE, 2013d, p. 20).

O olhar lançado centralizou-se nas maiores produções daquele cenário, a fim de observar o entorno dos podcasts que reúne o que pode se supor constituir a maior parte dos usuários da podosfera nacional. De modo a auxiliar no levantamento das produções de maior visibilidade no país, foi seguida uma perspectiva comparativa considerando o número usual de postagens de comentários pelos usuários entre podcasts comerciais e não comerciais. Concentrado no mesmo objetivo, foi feito uso dos números do projeto "Prêmio Podcast" 8 em sua edição de 2009, a mais recente até a publicação do presente artigo. O aludido concurso consistiu em uma eleição do público que votou pela internet para eleger os melhores podcasts do Brasil.

8 Embora o site do projeto já esteja extinto, em 2013 o twitter da iniciativa ainda encontra-se disponível em: <twitter.com/premiopodcast>. 
Ainda no intuito de elencar as principais produções nacionais, os dados de audiência da Podpesquisa $2009^{9}$ foram utilizados como referência. Conforme indicou a investigação de Freire (2013e), tal pesquisa pode ser qualificada como o maior levantamento estatístico sobre o uso brasileiro de podcast até 2012, e, embora conte com limitações metodológicas, "caracteriza-se como iniciativa apta a traçar um perfil representativo da apropriação social do podcast no Brasil” (FREIRE, 2013e). Porém, vale salientar que no olhar descrito neste momento não foram deixados de lado programas de menor audiência, que acabaram formando parte significativa dos episódios consultados.

No que diz respeito à seleção das fontes diretamente consideradas - os específicos programas citados neste artigo -, é possível afirmar que essa não se restringiu à busca por representatividade estatística, mas esteve "mais ligada à significação e à capacidade que as fontes têm de dar informações confiáveis e relevantes sobre o tema de pesquisa" (DUARTE, 2006, p. 68). Desse modo, foi feito uso, segundo a classificação de Duarte, de "seleção intencional”, na qual “o pesquisador faz a seleção por juízo particular, como conhecimento do tema ou representatividade subjetiva" (DUARTE, 2006, p. 68).

\section{4 - Estratégia original}

A classificação que buscará ser aprofundada por este trabalho partiu da investigação que apontou a influência basilar que o modo de produção possui na determinação da natureza das produções educacionais em podcast. Nessa direção, observou-se entre os programas constituídos por diferentes origens produtivas claras tendências ao estabelecimento de diferenças relacionadas a fatores educativamente relevantes em tais produções. As falas de um podcast elaborado a partir da gravação de uma aula, por exemplo, revelaram uma notada inclinação a constituírem-se por uma menor dinâmica e celeridade que aquelas elaboradas originalmente para serem vinculadas em podcast. Tal relação implica em distinções que influenciam a capacidade dos programas de despertarem a atenção dos ouvintes em situações de atenção dividida,

9 Disponível em: <www.podpesquisa.com.br>. 
típicas da audição de podcast no Brasil ${ }^{10}$, e, assim, contribuem para a determinação dos diferenciados resultados educativos que aquelas produções poderão proporcionar.

Em razão das relações observadas, elencou-se a esfera produtiva como critério de classificação de podcasts, designados a partir da base produtiva que detém. Dessa forma, os podcasts foram classificados nos três tipos já citados: o podcast Registro, que consiste na captura de falas realizadas em aulas, palestras, cursos e afins; o do tipo Ampliação Tecnológica, que se refere à transposição de materiais de outras tecnologias - como programas de rádio ou CDs educativos - para o podcast; o podcast Produção Original, que se trata de um programa elaborado originalmente para podcast, considerando, assim, desde o princípio, as características particulares dessa tecnologia.

\section{5 - Estrutura do sistema classificatório}

A elaboração das classificações desenvolvidas neste artigo serão direcionadas a estender as divisões educacionais dos podcasts Produção Original, Registro e Ampliação Tecnológica. Desta feita, as designações a serem especificadas serão constituídas a partir de uma estrutura relacionada às classificações anteriormente elaboradas. Em outras palavras, o podcast do tipo Lúdico, por exemplo, será definido como uma segunda classificação aplicável tanto aos podcasts Produção Original, quanto àqueles Registro e Ampliação Tecnológica. Desta feita, poderá haver tanto programas "Produção original Lúdico”, quanto “Registro - Lúdico” e “Ampliação Tecnológica - Lúdico”.

É também necessário ressalvar que as classificações a serem desenvolvidas se tratam de elaborações referenciais, não se propondo a separar categoricamente uma modalidade de podcast educacional de outra. Nessa medida, o critério aqui elencado é o de buscar o que mais destaca educativamente uma produção para, a partir desse aspecto, classificá-la.

10 Segundo dados da Podpesquisa, a maioria dos ouvintes $(66,74 \%)$ escutam os programas enquanto executam outras tarefas. 


\section{2 - Classificações de Usos Educacionais do Podcast}

É razoável afirmar que um dos acréscimos mais patentes que o podcast demonstra poder prover no campo educacional consiste na ampliação dos tempos e espaços do exercício educativo. Em vista disso, constata-se ser possível classificar como Ampliação Espacial-Cronológica o podcast que visa ampliar as práticas educacionais levando a novas instâncias físicas e temporais expressões tipicamente restritas aos muros da escola. Essa constatação associa, em grande medida, o tipo de podcast aludido àqueles da modalidade Registro.

Todavia, esta perspectiva não impossibilita a realização de podcasts Ampliação Espacial-Cronológica do tipo Produção Original. Tal associação pode ocorrer, por exemplo, pelo uso de uma gravação feita para levar a fala docente além da escola, contudo, especificamente realizada para atender às demandas por maior dinamicidade de falas para podcast em uma realização Produção Original. Programas que se inserem nesse perfil são registrados na bibliografia da área em pesquisas como a de Moura (2006), na qual a estudiosa examina o exercício do Podcast de Literatura Portuguesa, projeto voltado à realização de falas docentes em "podcasts para aprender e rever conteúdos programáticos de Literatura Portuguesa" (MOURA, 2006, p. 48).

Outra utilização igualmente presente na bibliografia educacional que trata do podcast é aquela voltada à elaboração de materiais didáticos em podcast, como apresentação de conteúdos, resumo de aulas, entrevistas, matérias jornalísticas, leituras faladas e afins. Estudos como os de Canfil; Rocha; Fachi (2010) e Farias; Boas; Dias (2007) tratam de experiências que seguem às direções supracitadas.

É cabível que tal apropriação da tecnologia aqui tratada seja designada como um podcast Material Didático. Tal tipo de produção mostra-se bastante veiculado às modalidades Produção Original e Ampliação Tecnológica, por poder partir tanto da elaboração de programas em ambiente controlado (estúdio, por exemplo), quanto ser apto a realizar-se pela transposição de produções radiofônicas para podcast. Na modalidade Produção Original, o Material Didático detém maior controle do ambiente de gravação, o que possibilita que este tipo de podcast seja identificado por uma destacada qualidade técnica, geralmente superior à captura de aulas, palestras e afins. Além disso, 
costuma distinguir-se por uma maior dinâmica por meio do uso de edição, o que é possível através da retirada de pausas e inserção de ênfases através de música e efeitos de sonoplastia. Os fatores referidos costumam culminar em produções mais céleres e dinâmicas, quesitos, estes, que potencializam a repercussão dos programas junto aos ouvintes.

No seguimento da investigação corrente, observa-se que a apropriação do podcast para o trabalho de línguas estrangeiras ocupa um significativo espaço na esfera escolar daquela tecnologia. São diversas as experiências, como as examinadas por Menezes (2009) e Vasconcelos (2009), que tratam de tal uso, fato, este, que ocasiona a necessidade de incluir a utilização aludida nas categorias aqui propostas.

Todavia, vale salientar que o uso do podcast na direção tratada neste momento pode ser estendido ao vernáculo. Embora a bibliografia da área pouco se atente a tal aplicação, a observação da podosfera brasileira demostra que, nesta, o podcast revela-se meio de desenvolvimento expressivo para indivíduos carentes de um melhor desenvolvimento oral. Podcasts como o Nerdcast ${ }^{11}$ e o Podcast de Tanguinhas ${ }^{12}$ contam com participantes que, enfrentando grandes dificuldades nos primeiros episódios dos programas, seja por timidez ou dificuldades de articulação, demonstraram uma significativa evolução de sua expressão ao longo das edições dos programas. Por essa razão, uma consideração ampla das esferas educacionais do podcast demanda que a classificação aqui tratada contemple o podcast Desenvolvimento Oral, definido como aquele voltado ao melhoramento da competência oral, seja na língua materna ou estrangeira.

Indo além da observação dos contextos escolares, é possível elaborar um tipo classificativo referente à outra importante utilização educativa do podcast que se encontra à margem da bibliografia da área. A aludida apropriação consiste do podcast Expressão de Vozes. Este consiste na utilização do podcast para dar vazão a vozes que possuem pouco espaço no âmbito social vigente, ou mesmo no contexto escolar que ocupam, por veicularem temas e posicionamentos não hegemônicos nos locais que habitam. Têm-se, assim, uma prática que se mostra educativa em razão de atender a uma 
importante demanda do referencial teórico aqui eleito, o qual, a partir das concepções de Paulo Freire, entende a educação como necessariamente pautada pelo diálogo, desenvolvido em um processo no qual "os homens se educam entre si, mediados pelo mundo" (FREIRE, 2003, p. 68).

A observação da podosfera oferece subsídio para outra classificação de podcasts educacionais, em um modo de podcast denominado de Lúdico. Este consiste no uso, em podcast, de jogos, teatralizações sonoras e outras ações lúdicas como instrumento de trabalho pedagógico. Considerando a importância de tais práticas ao desenvolvimento do interesse dos Sujeitos em relação a componentes curriculares (ALVES, 2006; DOHME, 2003, entre outros), observa-se que as características próprias do podcast - facilidade e agilidade de produção - propiciam a ampliação do uso do áudio para elaboração de tais práticas educativas.

No campo em questão, inserem-se desde a dramatização de histórias faladas até o uso de jogos. Como exemplo deste último, é possível citar o jogo “verdade ou mentira?", realizado pelo podcast Guanacast ${ }^{13}$, no qual são veiculadas notícias de caráter peculiar, todas aparentemente pouco críveis, das quais apenas algumas são verdadeiras. Assim, os leitores são estimulados a pesquisar para poderem discernir quais notícias são verdadeiras e quais são falsas. No campo da dramatização, o podcast Escriba Cafée $e^{14}$ demonstra a essência de um podcast Lúdico. São tratados naquele programa temas dentro da área da literatura a partir de um detido trabalho de sonoplastia que permite ceder ritmo e cadência às exposições, levando o ouvinte a mergulhar no clima do tema retratado.

O exercício do podcast em contextos não escolares aponta, ainda, para outra modalidade de uso: Introdução Temática. Tal classificação diz respeito à elaboração de um programa para, auxiliado pela atmosfera informal típica do exercício nacional do podcast (FREIRE, 2013d, p. 214), despertar o interesse dos ouvintes por uma determinada temática. Observa-se essa apropriação em diversas produções da podosfera, como o Nerdcast, relacionado a temas como ciência, história, literatura; o Guanacast, que trata da 
temática tecnológica; o Decodificando que aborda, além do último tema citado, as áreas da Biologia e do Direito.

O podcast Introdução Temática, através do uso de uma linguagem informal, tom dinâmico e riqueza expressional advinda do uso de recursos de sonoplastia, costuma dedicar-se à apresentação dos temas tratados de forma sintetizada, simples e coloquial. Dessa maneira, o uso do podcast acaba por contribuir para que os alunos se aproximem dos conteúdos, reservando para momentos posteriores o aprofundamento dos assuntos tratados.

No contexto escolar, a bibliografia que pensa educativamente o podcast registra um uso primordialmente informativo dessa tecnologia. Trata-se da apropriação do podcast que pode ser classificada como Trânsito Informativo. Neste tipo, o podcast é utilizado como meio para a troca de informes entre os participantes de um dado contexto educativo. Essa prática contempla a veiculação de instruções relativas à realização de trabalhos escolares, orientações de estudo, bem como apresentação e resolução de exercícios, por exemplo. O uso é tratado com brevidade por Carvalho; Aguiar; Maciel (2009, p.97), que o apontam como detentor de um significativo potencial escolar do podcast.

A perspectiva dialógica do podcast é ressaltada pelos programas da categoria “Ponto de encontro". Estes se relacionam ao uso do podcast como mote para reunião de Sujeitos que compartilham afinidades, a fim de viabilizarem um debate posterior permeado pelas temáticas que possuam em comum, abordadas nos programas. No âmbito da podosfera, observa-se que os podcasts, geralmente associados a blogs, fóruns e/ou comunidades de redes sociais, costumeiramente atuam como agregadores de pessoas para discussão das temáticas tratadas.

Já o Podcast para Surdos é, como visto anteriormente, aquele dedicado a dispor para deficientes auditivos a oralidade dos programas. Tal modalidade de podcast encontra-se em curso no Brasil por meio de versões inclusivas de produções como o Podsemfio, de Beatriz Kunze. Segundo ela, o Podcast para Surdos reproduz em significativa medida a oralidade das expressões originais dos programas, considerando 
que "o deficiente auditivo está ali lendo e está tendo a sensação de uma conversa coloquial (...)" (KUNZE, 2011, n. p.).

O Podcast Cooperativo, por sua vez, nasce do encontro dos referenciais da cooperação definidos por Célestin Freinet (1998) com o processo produtivo da tecnologia aqui tratada. A cooperação freineteana elenca o trabalho como instância de encontro dos Sujeitos para a ação de aprender, rejeitando o recebimento de concepções terceiras em favor do exercício da construção conjunta do conhecimento. Nesta, os indivíduos apropriam-se criticamente das informações disponíveis envoltos em uma atmosfera laboriosa espontânea e democrática, a partir da qual podem por em curso a máxima do "aprender a fazer fazendo".

Desta feita, o podcast Cooperativo consiste em uma produção na qual importa menos o conteúdo realizado e mais o processo seguido para tal. Nesse caminho, busca-se o progresso educativo por meio da convivência laboriosa dos envolvidos, aproximados pela "fraternidade do trabalho" (FREINET, 1998, p. 335), advinda da repartição democrática das diversas etapas produtivas inerentes à realização de um podcast. Nesse cenário, o podcast Cooperativo consiste de uma realização na qual o programa é mero pano de fundo para o trabalho educacional posto em curso em seu entorno, no qual é desenvolvido um trabalho que busca ultrapassar quesitos estritamente coercitivos, partindo, para isso, de uma ação motivada pelo interesse laboral inerente a Sujeitos que são organizados democraticamente.

Diante das classificações elaboradas, observa-se que estas, pela forte caracterização on-line do podcast, também são adequadas para ações educacionais ocorridas a distância. O entendimento apresentado, portanto, torna dispensável o desenvolvimento de uma classificação “Podcast a Distância”.

Assim, elaborado o conjunto de classificações proposto, torna-se possível vislumbrar suas limitações. A partir disso, constata-se que as classificações aqui designadas se demonstram incapazes de contemplar todas as possíveis apropriações educacionais do podcast. A incipiência das investigações classificativas do podcast educacional, por si só, inviabilizaria tal pretensão. Além disso, o suposto esgotamento da discussão abordada neste artigo implicaria em um objetivo desarticulado com a dinâmica que caracteriza a evolução dos usos educacionais das tecnologias. Em vista disso, 
constata-se que as classificações aqui desenvolvidas servem ao oferecimento de uma estratégia de classificação constituída por um alicerce coeso e articulado com a atualidade educacional do podcast, constituindo, assim, uma referência que busca organizar o pensamento da área e, principalmente, enriquecer as discussões iniciais que aborda.

\section{Considerações Finais}

O estágio incipiente das estratégias classificativas do podcast suscita 0 desenvolvimento de classificações que considerem amplamente a atualidade educacional dessa tecnologia. Nesse caminho, as classificações propostas por Freire (2013c) demonstraram demandar um aprofundamento que considere, além da origem produtiva, os específicos usos educativos dos quais dispõe o podcast.

Para tanto, mostrou-se necessário lançar um olhar não limitado à esfera escolar daquela tecnologia, mas que contemplasse diversas aplicações educacionais do podcast que se exercitam fora dos contextos escolares. Tal prisma propiciou que fosse elaborado um sistema de classificações que estendesse o anteriormente desenvolvido, contemplando, nesse intuito, diversas apropriações educacionais vistas em múltiplos cenários escolares e não escolares. A partir desses procedimentos, chegou-se a um sistema de classificações mais extenso.

Segundo a taxionomia aqui tratada, os podcasts são classificados educativamente como Registro, dedicado a capturar falas educacionais e estendê-las a outras esferas temporais e espaciais; Ampliação Tecnológica, promotor da transposição de materiais de outras tecnologias para podcast; Produção Original, realizado originalmente como podcast. Podendo partir de quaisquer dessas três categorias, os podcasts são capazes de deter uma segunda classificação, relacionada ao seu específico uso educacional. Tais classificações organizam os podcasts educativos nas seguintes categorias:

Ampliação Espacial-Cronológica: Trata-se da gravação e distribuição por demanda de falas direcionadas à expressão em aulas, palestras, cursos e afins. 
Material Didático: Consiste na elaboração de materiais didáticos nativamente em podcast, como apresentação de conteúdos, resumo de aulas, entrevistas, matérias jornalísticas, leituras faladas e afins.

Desenvolvimento Oral: Encontra-se voltado ao desenvolvimento da competência oral em língua estrangeira ou no vernáculo, aproveitando-se da atmosfera de controle do podcast nos momentos de expressão e audição desta.

Expressão de Vozes: Consiste na utilização do podcast para dar vazão a vozes que possuem pouco espaço no âmbito escolar por veicularem temas e posicionamentos não hegemônicos nesse cenário institucional.

Lúdico: Trata-se do uso, em podcast, de jogos, dramatizações e outras ações lúdicas como instrumento de trabalho pedagógico.

Introdução Temática: Diz respeito à elaboração de programas para, auxiliados pelos quesitos típicos do podcast, despertarem o interesse dos ouvintes por determinadas temáticas.

Trânsito Informativo: Refere-se à troca de informes via podcast entre os participantes de um contexto educativo. Essa prática contempla a veiculação de instruções relativas à realização de trabalhos escolares, orientações de estudo, bem como apresentação e resolução de exercícios, entre outras práticas afins.

Ponto de Encontro Comunicativo: Relaciona-se ao uso do podcast como mote para reunião de Sujeitos que compartilham afinidades, a fim de viabilizar um debate posterior permeado por temáticas que possuam em comum e que sejam tratadas nas produções.

Cooperativo: Consiste em um podcast no qual o conteúdo produzido figura como pano de fundo para a convivência laboral dos produtores, os quais, partindo de um interesse espontâneo, compartilham democraticamente as diversas etapas produtivas envolvidas na elaboração de um programa.

Podcast para surdos: Trata-se de um podcast no qual a oralidade dos falantes é reproduzida parcialmente, por meio de transcrição, de modo a dispor tais falas para deficientes auditivos. 
A partir das designações construídas, constata-se que as estratégias classificativas elaboradas no presente artigo promovem a maturação do pensamento educacional do podcast, o qual, caso busque um desenvolvimento rigoroso, não pode prescindir de um sistema classificativo que designe de modo claro, coeso e articulado com a atualidade o desenvolvimento das apropriações do podcast nos mais diversos contextos educacionais.

\section{Referências}

ALVES, Eva Maria Siqueira. A ludicidade e o ensino de matemática. Campinas: Papirus, 2006.

BOTTENTUIT JUNIOR, João Batista; LISBÔA, Eliana Santana; COUTINHO, Clara Pereira. Podcast: uma revisão dos estudos realizados no Brasil e em Portugal. In: ENCONTRO SOBRE PODCASTS, Braga, Portugal, 2009. Actas. Braga: CIED-UM, 2009. Disponível em: <http://repositorium.sdum.uminho.pt/handle/1822/9421>. Acesso em: 29 nov 2013. 
CANFIL, Daniele Cristina; ROCHA, Diana; FACHI, Camila Candeia Paz. Podcast: o universo midiático em sala de aula. In: CONGRESSO DE CIÊNCIAS DA COMUNICAÇÃO NA REGIÃO SUL, XI, Novo Hamburgo (RS) 17 a 19 de maio de 2010 Papers. [Novo Hamburgo]: Intercom, 2010. p. 508. Disponível em:

<http://www.intercom.org.br/papers/regionais/sul2010/resumos/R20-0291-1.pdf>. Acesso em: 01 out. 2013.

CARVALHO, Ana Amélia; AGUIAR, Cristina; MACIEL, Romana. Taxonomia de Podcasts: da criação à utilização em contexto educativo. In: ENCONTRO SOBRE PODCASTS, Braga, Portugal, 2009. Actas. Braga: CIED-UM, p. 96-109, 2009. Disponível em: <repositorium.sdum.uminho.pt/bitstream/1822/10032/1/Carvalho\%20et\%20al-2009Taxonomia-Enc\%20sobre\%20Pocasts.pdf>. Acesso em: 09 ago. 2012.

CRUZ, Sónia Catarina. O podcast no ensino básico. In: CARVALHO, A. A. (Org.). In: ENCONTRO SOBRE PODCASTS, Braga, Portugal, 2009. Actas. Braga: CIED-UM, p. 65-80, 2009. Disponível em: <http://repositorium.sdum.uminho.pt/bitstream/1822/9991/1/Cruz-2009Enc\%20sobre\%20Podcasts.pdf>. Acesso em: 16 de novembro de 2012.

DOHME, Vania D'Angelo. Atividades lúdicas na educação: o caminho de tijolos amarelos do aprendizado. Petrópolis: Vozes, 2003.

DUARTE, Jorge. Entrevista em profundidade. In: DUARTE, Jorge; BARROS, Antônio (Orgs.). Métodos e técnicas de pesquisa em comunicação. 2. ed. São Paulo: Atlas, 2006.

FARIA, Ádila; BOAS, Maria Helena Vilas; DIAS, Pedro. Podcasting "era uma vez...": utilização pedagógica na educação. In DIAS, Paulo; FREITAS, Cândido Varela de; SILVA, Bento; OSÓSIO, António; RAMOS, Altina (Orgs.). In: CONFERÊNCIA INTERNACIONAL DE TECNOLOGIAS DE INFORMAÇÃO E COMUNICAÇÃO NA EDUCAÇÃO, V, Challenges, 2007. Actas. Braga: UM.p. 260-262. Disponível em:

<http://erte.dge.mec.pt/files/@crie/1259773520_podcasting_era_uma_vez.pdf>. Acesso em: 01 dez 2013.

FREINET, Célestin. A educação do trabalho. São Paulo: Martins Fontes, 1998.

FREIRE, Eugênio Paccelli Aguiar. Aplicações escolares do podcast. In: CONGRESSO NACIONAL DE AMBIENTES HIPERMÍDIA PARA APRENDIZAGEM (CONAHPA), 6, João Pessoa, 2013. Anais..., 2013a. Disponível em: <http://66.7.199.78/ andreenr/AnaisCONAHPA-2013/assets/aplicacoes_escolares_eugenio.pdf>. Acesso em: 01 out. 2013.

FREIRE, Eugênio Paccelli Aguiar. Conceito educativo de Podcast: um olhar para além do foco técnico. Educação, Formação \& Tecnologias, v. 6, n. 1, p. 35-51, 2013b. Disponível em: <eft.educom.pt/index.php/eft/article/view/340>. Acesso em: 13 out. 2013.

FREIRE, Eugênio Paccelli Aguiar. Construção de uma estratégia de classificação para podcasts na educação. Revista Inter Ação, v. 38, n. 3, p. 711-730, 2013c. Disponível em: < http://www.revistas.ufg.br/index.php/interacao/article/view/20810>. Acesso em: 21 set. 2014. 
FREIRE, Eugênio Paccelli Aguiar. Distinções educativas entre rádio e podcast. Revista PRISMA. COM, n. 18, 2012. Disponível em:

<revistas.ua.pt/index.php/prismacom/article/view/1418>. Acesso em: 13 out. 2013.

FREIRE, Eugênio Paccelli Aguiar. O podcast como ferramenta de educação inclusiva para deficientes visuais e auditivos. Revista Educação Especial, Santa Maria, v.24, n. 40, maio/ago. 2011. Disponível em: <cascavel.ufsm.br/revistas/ojs-

2.2.2/index.php/educacaoespecial/issue/view/210/showToc>. Acesso em: 13 out. 2013.

FREIRE, Eugênio Paccelli Aguiar. Podcast na educação brasileira: natureza, potencialidades e implicações de uma tecnologia da comunicação. Natal, 2013d. 338 p. Tese (Doutorado em Educação) - Universidade Federal do Rio Grande do Norte, Centro de Ciências Sociais Aplicadas, Rio Gande do Norte, 2013. Disponível em:

<http://bdtd.bczm.ufrn.br/tde_busca/arquivo.php?codArquivo=6532>. Acesso em: 13 out. 2013.

FREIRE, Eugênio Paccelli Aguiar. Podcast: novas vozes no diálogo educativo. Interacções, n. 23, p. 102-127, 2013e. Disponível em: <revistas.rcaap.pt/interaccoes/article/view/2822>. Acesso em: 13 out. 2013.

FREIRE, Eugênio Paccelli Aguiar. Podpesquisa: análise educativa de uma pesquisa sobre podcasts. Poiésis: Revista do Programa de Pós-Graduação em Educação, v. 7, n. 11, p. 149167, 2013e. Disponível em:

<http://portaldeperiodicos.unisul.br/index.php/Poiesis/article/view/1635>. Acesso em: 01 dez. 2013.

FREIRE, Paulo. Pedagogia do oprimido. 35. ed, São Paulo: Paz e Terra, 2003.

KETTERL, Markus; MERTENS, Robert; MORISSE, Karsten. Alternative content distribution channels for mobile devices. In: MICROLEARNING CONFERENCE LEARNING WORKING \& LIVING IN NEW MEDIA SPACES, 1, Innsbruck, Austria, 2006. [Papers]. 2006. Disponível em <http://www.informatik.uni-osnabrueck.de/papers_pdf/2006_02.pdf >. Acesso em: 25 de setembro de 2008.

KUNZE, Beatriz. Entrevista oral (via podcast). Entrevistador: EugênioPaccelli Aguiar Freire. Local, Maio de 2011. [Arquivo de áudio digital MP3]

MEDEIROS, Macello Santos de. Podcasting: produção descentralizada de conteúdo sonoro. In: CONGRESSO BRASILEIRO DE CIÊNCIAS DA COMUNICAÇÃO, 28. 2005. Rio de Janeiro. Anais... São Paulo: Intercom, 2005. Disponível em: < http://www.portcom.intercom.org.br/pdfs/84071885084469832222151638470992010359. pdf >. Acesso em: 14 de Abril de 2012.

MENEZES, Célia Maria Cardoso de Abreu; QUINTANILHA, Vasconcelos. Utilização de dispositivos móveis na escola do séc. XX I: o impacto do podcast no processo ensino aprendizagem da língua inglesa no $7^{\circ}$ ano do $3^{\circ}$ ciclo do ensino básico. 2009. Disponível 
em: < http://repositorio.uportu.pt/jspui/bitstream/123456789/530/2/TMI\%2022.pdf>. Acesso: 01 dez 2013.

MOURA, Adelina; CARVALHO, Ana Amélia. Podcast: uma ferramenta para usar dentro e fora da sala de aula. In: Rui José \& Carlos Baquero (Eds). Proceedings of the Conference on Mobile and Ubiquitous Systems. Universidade do Minho, Guimarães, 2006, p. 155-158. Disponível em: <http://ubicomp.algoritmi.uminho.pt/csmu/proc/moura-147.pdf>. Acesso em: 01 dez. 2013.

PERUZZO, Cecilia Krohling. Observação participante e pesquisa-ação. IN: DUARTE, Jorge ; BARROS, Antônio (Orgs.). Métodos e técnicas de pesquisa em comunicação. 2. ed. São Paulo: Atlas, 2006.

PRIMO, Alex Fernando Teixeira. Para além da emissão sonora: as interacções no podcasting. Intertexto, Porto Alegre, 2005. Disponível em:

<http://www.lume.ufrgs.br/handle/10183/26568>. Acesso em: 14 de Março de 2011.

VASCONCELOS, Sandra Vieira. Utilização de podcasts no ensino de inglês língua estrangeira: estudo exploratório em contexto não-formal e não-presencial. 2009, 00 f. Dissertação (Mestrado em Multimédia em Educação) - Universidade de Aveiro. Departamento de Didáctica e Tecnologia Educativa, Avieiro, 2009. Disponível em: < http://ria.ua.pt/handle/10773/1398>. Acesso em: 01 dez. 2013. 